\title{
Macrophage CGI-58 Attenuates Inflammatory Responsiveness via Promotion of PPARY Signaling
}

\author{
Dan Yang Haimei Chen Xu Zeng Ping Xie Xincun Wang Chang Liu \\ Department of Computational Biology and Bioinformatics, Institute of Medicinal Plant Development, \\ Chinese Academy of Medical Sciences and Peking Union Medical College, Beijing, PR China
}

\section{Key Words}

CGI-58 • PPARs • Inflammation • ROS • Mitochondrial dysfunction

\begin{abstract}
Background/Aims: Comparative gene identification-58 (CGI-58), an adipose triglyceride lipase (ATGL) coactivator, strongly promotes ATGL-mediated triglyceride (TG) catabolism. Beyond its function in promoting lipolysis, other features of CGI-58 have been proposed. Here, we investigated the role of CGI-58 in the regulation of inflammatory responsiveness in macrophages. Methods: Macrophage-specific GCI-58 transgenic mice (TG) and wild type mice (WT) were fed a high fat diet (HFD), and RAW264.7 cells were treated with lipopolysaccharide (LPS). The peroxisome proliferator-activated receptor (PPAR) signaling was detected. The inflammatory responsiveness and mitochondrial function were examined. Results: TG mice showed lower serum levels of proinflammatory cytokines and better mitochondrial function in macrophages compared with WT control. Knockdown of CGI-58 in RAW264.7 cells aggravated LPS-induced inflammation and mitochondrial dysfunction. CGI-58 overexpression and silencing in macrophages induced and inhibited PPARY expression and activity, respectively. Most importantly, the PPAR $\gamma$-specific agonist rosiglitazone significantly suppressed inflammation and mitochondrial dysfunction induced by CGI-58 deficiency. Furthermore, knockdown of PPARY in macrophages significantly dampened the role of CGI-58 in suppression of inflammation and mitochondrial dysfunction. Interestingly, CGI-58 inhibited histone deacetylation and the recruitment of histone deacetylase (HDAC) to the PPAR p promoter. Finally, ATGL deficiency did not affect inflammatory responsiveness and PPARY signaling in macrophages. Conclusion: These results demonstrate that macrophage CGI-58 enhances PPAR signaling and thus suppresses inflammatory responsiveness and mitochondrial dysfunction.
\end{abstract}




\section{Cellular Physiology and Biochemistry \\ Cell Physiol Biochem 2016;38:696-713 \\ \begin{tabular}{l|l}
\hline DOI: $10.1159 / 000443027$ & (c) 2016 The Author(s). Published by S. Karger AG, Base
\end{tabular} \\ Published online: February 15, 2016 www.karger.com/cpb \\ Yang et al.: Macrophage CGI-58 Inhibits Inflammation}

\section{Introduction}

Comparative gene identification 58 (CGI-58), also known as $\alpha / \beta$-hydrolase-domain containing- 5 (ABHD5), is the fifth member of the $\alpha / \beta$-hydrolase fold family. Lacking intrinsic lipase activity, CGI-58 functions as a coactivator of adipose triglyceride lipase (ATGL) to robustly increase its in vitro triglyceride hydrolase activity $[1,2]$. In humans, mutation of CGI-58 causes neutral lipid storage disease with ichthyosis (NLSDI), also designated Chanarin-Dorfman syndrome (CDS), a rare autosomal recessive neutral lipid storage disease characterized by ichthyosis (thickened dry skin) and the accumulation of triglyceride-rich lipid droplets in most tissues and cell types, but not in fat [3]. Patients with mutated ATGL alleles also develop neutral lipid storage disease, but some clinical manifestations differ from those observed in NLSDI patients. The divergent phenotypes between CGI-58 and ATGL mutations in patients provide compelling evidence for an ATGL-independent function of CGI-58. In a previous study, CGI-58 has been reported to function as an intrinsic CoAdependent lysophosphatidic acid acyltransferase (LPAAT) to generate phosphatidic acid (PA) [4]. However this finding was denied by the same group recently [5]. Currently, just a few studies have linked CGI-58 to inflammatory activation. In our preliminary findings, the serum levels of TNF $\alpha$ and IL- 6 were found to be decreased when CGI-58 was overexpressed in macrophages [6]. However the underlying molecular mechanisms for this association were largely unknown.

Peroxisome proliferator-activated receptors (PPARs) are ligand-activated transcription factors that belong to the nuclear receptor superfamily. PPARs are activated by free fatty acid. Although PPARs were initially characterized as regulators of metabolic diseases, recent studies have clearly demonstrated an important role for these nuclear receptors in inflammatory pathways and immunological regulation. PPAR family includes three members, encoded by distinct genes $(\alpha, \beta / \delta$, and $\gamma)$. The $\alpha, \beta$, and $\gamma$ receptors are present in macrophages, suggesting that they may be implicated in macrophage pathologies, such as inflammation [7]. Generally speaking, PPAR $\alpha$ plays a critical role in cellular uptake and $\beta$-oxidation in fatty acids, while PPAR $\beta$ and PPAR $\gamma$ modify inflammatory responsiveness [8]. However, few studies have so far addressed the correlation between CGI-58 and PPAR signaling. In our previous study, CGI-58 regulated PPAR expression. However its mechanisms are unclear [6]. It is possible that CGI-58 may mediate inflammation in a PPAR-dependent manner in macrophages.

Reactive oxygen species (ROS) are key mediators of inflammatory activation. It was shown that mitochondrial dysfunction triggered ROS accumulation and, therefore, inflammatory processes $[9,10]$. The aim of the present study was to detect the role of CGI-58 in the regulation of inflammation in macrophages. We provide evidence showing that macrophage CGI-58 suppresses ROS generation, mitochondrial dysfunction, and inflammatory responsiveness by promoting PPAR $\gamma$ signaling.

\section{Materials and Methods}

The study was reviewed and approved by the institutional ethics review board of the Peking Union Medical College (Beijing, China).

Chemicals and reagents

Anti-PPAR $\alpha$, anti-PPAR $\beta$, and anti-PPAR $\gamma$ antibodies were obtained from R\&R Systems; anti-HDAC1 and anti-HDAC2 were obtained from Affinity BioReagents; and anti-acetyl-H3, anti- $\beta$-actin, and HRPconjugated secondary antibodies were obtained from Cell Signaling Technology. All other chemicals were from obtained from Sigma. 


\section{Cellular Physiology Cell Physiol Biochem 2016;38:696-713 \\ \begin{tabular}{l|l|l} 
DOI: 10.1159/000443027 & (c) 2016 The Author(s). Published by S. Karger AG, Basel
\end{tabular} and Biochemistry Published online: February 15, 2016 www.karger.com/cpb}

Yang et al.: Macrophage CGI-58 Inhibits Inflammation

Generation and characteristics of transgenic mice

The cDNA of mouse CGI-58 was subcloned into a plasmid that contained the human SRA (scavenger receptor A) promoter/enhancer to selectively express the gene in macrophages [6]. The resulting fusion transgene was referred to as SRA-CGI-58. The SRA-CGI-58 transgene construct was microinjected into C57BL/6 (B6) embryos according to standard protocols, and the obtained founders were expanded by crossing them into the B6 strain. Four CGI-58 transgene-positive founder lines were established, and the line with the highest level of CGI-58 expression in macrophages was selected for further study. Mouse genotypes were determined by PCR analysis of DNA contained in tail-cut samples using the primers $5^{\prime}$-GCC GCT TAC TCA CTG AAG TACCC-3' and 5'-CTC AAA CGC TGC ACT AGA CTT AACC-3', which amplify a 209 bp DNA fragment that is specific to the CGI-58 DNA in the transgenic mice.

\section{Diet and feeding}

All mice were housed in a specific pathogen-free animal facility in plastic cages at $22^{\circ} \mathrm{C}$ and maintained with a daylight cycle from 6 AM to 6 PM. The mice were provided with water and a standard chow diet ad libitum, unless otherwise stated. All animal procedures were approved by the Institutional Animal Care and Use Committee at Peking Union Medical College.

At 8 weeks of age, mice were fed a synthetic high fat diet (HFD) containing $45 \%$ energy from lard (16:0 $=23.3 \%, 18: 0=15.9 \%, 18: 1=34.8 \%$, and 18:2 = 18.7\%). After being fed a HFD for 18 weeks, the mice were sacrificed to collect plasma and peritoneal macrophages.

\section{Peritoneal macrophage isolation}

Mice received an i.p. injection of $3 \mathrm{ml} \mathrm{3 \%}$ thioglycollate. After 4 days, peritoneal macrophages were isolated from sacrificed animals by washing the peritoneal cavity with RPMI 1640 medium containing $0.5 \%$ bovine serum albumin (BSA). Cells were then plated on culture plates. After 4 hours of incubation, the non-adhering cells were removed by washes with culture medium, and the adherent cells were used as peritoneal macrophages for experiments.

\section{siRNA transfection}

Macrophages were cultured and grouped. At 75 - 80\% confluence, cells were transfected with 100 nmol/ L CGI-58 siRNA, PPAR $\gamma$ siRNA, ATGL siRNA, or non-targeting siRNA, all of which were obtained from Dharmacon, according to the manufacturer's instructions. The non-targeting siRNA was used as a transfection control to examine the non-sequence-specific effects of the transfected siRNAs.

\section{Proinflammatory cytokine ELISA}

Necropsy blood samples were collected from mice following a 4 hour fast during the light cycle. Plasma concentrations or cell culture supernatant concentrations of IL-1 $\beta$, IL-6, TNF $\alpha$, and MCP- 1 were determined using the indicated ELISA kits (R\&D Systems) according to the manufacturer's instructions.

\section{Quantitative PCR analysis}

Total RNA was extracted using Trizol reagent, and mRNA levels were detected using quantitative realtime PCR (qPCR). Cyclophilin was used as an internal control, and gene expression levels were calculated based on the delta-Ct method. The mRNA levels for each gene represented the observed amount relative to the amount in the control group, which was arbitrarily standardized to one. The primer sequences that were used for qPCR are available upon request.

\section{Western blot analysis}

Immunoblotting was performed according to previously described protocols $[2,11]$. To quantify protein signals, we subtracted background and normalized the value to $\beta$-actin. The data from each group were then expressed as a fold change of the control.

PPAR activity assay

Nuclear extracts of collected cells were prepared using a nuclear extraction kit (Active Motif, Carlsbad, CA, USA). PPAR $\alpha, \beta / \delta$, and $\gamma$ activities were quantified using the PPAR $\alpha, \beta / \delta$, and $\gamma$ Transcription Factor 


\section{Cellular Physiology Cell Physiol Biochem 2016;38:696-713 \begin{tabular}{ll|l}
\cline { 2 - 2 } DOI: 10.1159/000443027 & (c) 2016 The Author(s). Published by S. Karger AG, Basel
\end{tabular} and Biochemistry Published online: February 15, 2016 www.karger.com/cpb}

Yang et al:: Macrophage CGI-58 Inhibits Inflammation

Assay Kit (Cayman Chemical, USA) respectively. Briefly, these kits were ELISA-type formats with immobilized double-stranded DNA (dsDNA) sequences containing PPAR $\alpha, \beta / \delta$, or $\gamma$ response elements. A primary antibody recognized an accessible epitope on the PPAR $\alpha, \beta / \delta$, or $\gamma$ protein that binds dsDNA sequences in the 96-well plate. A secondary HRP-conjugated antibody was added to provide a sensitive colorimetric readout at $450 \mathrm{~nm}$. To quantify the PPAR $\alpha, \beta / \delta$, or $\gamma$ activities, the control values were set to 1 , and the fold changes of intervention groups were calculated.

\section{Firefly luciferase gene transactivation assay}

The 293T cells in 24-well plates were grown to 95\% confluence by the day of transfection. The cells were then transfected with $0.5 \mu \mathrm{g}$ of reporter plasmid, a specific PPAR $\gamma$-responsive expression vector of Photinus pyralis firefly luciferase (pPPRE-luc) (Genomeditech, Shanghai, China), $0.5 \mu \mathrm{g}$ of PPAR $\gamma$ expression plasmid (REBIO, Shanghai, China), 0.1-1.0 $\mathrm{g}$ of CGI-58 expression plasmid (REBIO, Shanghai, China), and $0.1 \mu \mathrm{g}$ of pRLL-Luc encoding Renilla reniformis luciferase (as an internal control for transfection efficiency). The cells were then washed twice with PBS and lysed in passive lysis buffer. Cell extract was incubated with luciferase assay reagents from the Stop \& Glo kit from Promega (Madison, WI). To normalize to transfection efficiency, firefly luminescence units were divided by Renilla lumincescence units. Signals of control (cells transfected with pPPRE-luc and pRLL-Luc) were set to100\%, and all the other groups were expressed relative to it.

Histone deacetylase activity assay

Histone deacetylase (HDAC) activity was determined using a fluorometric HDAC activity assay kit (BioVision Inc.). Nuclear extracts $(10 \mu \mathrm{g})$ were obtained from the cells. The substrate t-butoxycarbonylLys(AC)-amido-4-methylcoumarin (Boc-Lys(AC)AMC) was added, and the extracts were incubated at $37^{\circ} \mathrm{C}$ for $30 \mathrm{~min}$. After incubation, lysine developer was added, and the mixture was incubated again for $30 \mathrm{~min}$ at $37^{\circ} \mathrm{C}$. Fluorescence was detected using a Spectra Max M5 fluorescent plate reader (Molecular Devices) with excitation at $360 \mathrm{~nm}$ and emission at $460 \mathrm{~nm}$. All reactions were performed in duplicate.

\section{Chromatin immunoprecipitation assay}

A chromatin immunoprecipitation assay (ChIP) was performed. Briefly, cells were cross-linked with $1 \%$ formaldehyde for 10 minutes at room temperature. The cell lysate was sonicated at $30 \%$ output, on ice, four times with 15-second intervals and then pre-cleared with protein A-Sepharose 4B (Amersham Biosciences). The lysate was precipitated with primary antibodies to acetylated histone 3 (Ac-H3, $3 \mu \mathrm{g}$ ), HDAC1 $(4 \mu \mathrm{g})$ or HDAC2 $(4 \mu \mathrm{g})$ overnight at $4^{\circ} \mathrm{C}$. The DNA was purified using a QIA-AMP DNA purification system (Qiagen). PCR products were detected using primers specific for mouse PPAR $\gamma(-618 /-119)$, as follows: forward primer $5^{\prime}$-ATT TAA ATT TTA CTA GCCTT- ${ }^{\prime}$ ', and reverse primer $5^{\prime}$-GAC AAA ATG GTG TGT CATAA- $3^{\prime}$. Equal input DNA controls were assessed, and anti-Flag antibody (Sigma) served as the negative control.

\section{Determination of ROS generation}

Intracellular ROS levels were kinetically examined by measuring the oxidative conversion of cell permeable 2', 7'-dichlorofluorescein diacetate (DCFH-DA) to fluorescent dichlorofluorescein (DCF) in a Microplate Reader (Biotec, USA). Briefly, cells in 96-well culture dishes were washed with D-Hank's and incubated with DCFH-DA for $20 \mathrm{~min}$ at $37^{\circ} \mathrm{C}$. Then, the DCF fluorescence distribution in the cells was analyzed using a Microplate Reader at an excitation wavelength of $488 \mathrm{~nm}$ and an emission wavelength of $535 \mathrm{~nm}$.

Measurements of cellular ATP levels

Cellular ATP levels were determined using an ATP Assay Kit (Beyotime Institute of Biotechnology, China) according to the manufacturer's protocol. The value detected in CGI-58-silenced macrophages was normalized to that in the control, which was arbitrarily defined as $100 \%$.

Measurement of mitochondrial OCRs

Macrophages were seeded in 24-well plates for $24 \mathrm{~h}$ and mitochondrial oxygen consumption rate was measured at $37^{\circ} \mathrm{C}$ using an XF24 extracellular Analyzer (Seahorse Bioscience, USA) according to the 


\section{Cellular Physiology Cell Physiol Biochem 2016;38:696-713 \\ \begin{tabular}{ll|l} 
and Biochemistry & Dublished online: February 15, 2016 & $\begin{array}{l}\text { ( ) 2016 The Author(s). Published by S. Karger AG, Basel } \\
\text { www.karger.com/cpb }\end{array}$ \\
\hline
\end{tabular}}

Yang et al.: Macrophage CGI-58 Inhibits Inflammation

manufacturer's instructions. After the assays, plates were saved and protein concentration in each well was determined using a BCA assay (Thermo Fisher Scientific). The results are presented as pMoles $\mathrm{O}_{2} / \mu \mathrm{g}$ protein/min OCRs.

\section{Triglyceride hydrolase activity}

Triglyceride hydrolase activity was measured in the cytosolic extracts of macrophages from WT and TG mice fed a HFD for 18 weeks. For radioactive labeling of lipid droplets, macrophages were treated with $2.5 \mu \mathrm{Ci}\left[{ }^{3} \mathrm{H}-9,10\right]$-oleic acid/ml $+0.8 \mathrm{mM}$ cold oleic acid complexed to BSA for $16 \mathrm{~h}$. Cells were then washed with ice-cold PBS and centrifuged $\left(1000 \mathrm{~g}\right.$ at $4^{\circ} \mathrm{C}$ for $\left.10 \mathrm{~min}\right)$. The supernatant was removed and the cells were re-suspended in ice-cold hypotonic lysis medium (HLM) (20 mMTris-HCl, pH 7.4, 1 mM EDTA, 10 $\mathrm{mM}$ sodium fluoride, and protease inhibitor cocktail). To isolate lipid droplets, re-suspended cells were transferred to a Potter-Elvehjem tissue homogenizer and gently homogenized on ice. After centrifugation, the supernatant and floating fat layer were collected and adjusted to a final concentration of $20 \%$ sucrose in HLM. This was layered into a 13.2-ml ultracentrifuge tube, and gently overlaid with $5 \mathrm{ml}$ ice-cold HLM containing $5 \%$ sucrose. The remainder of the tube was filled with HLM and centrifuged at $28,000 \mathrm{~g}$ at $4{ }^{\circ} \mathrm{C}$ for 30 min using an SW40 rotor. The floating white lipid droplet layer was collected and TG contents were determined enzymatically. For the determination of macrophage triglyceride hydrolase activity, the cytosolic extracts were prepared by homogenizing cell samples in buffer A (0.25 M sucrose, 1 mM EDTA, 1 mM DTT, and protease inhibitor cocktail). Homogenate was centrifuged at $20,000 \mathrm{~g}$ for $30 \mathrm{~min}$ at $4^{\circ} \mathrm{C}$. The infranatant was removed and ultracentrifuged at $100,000 \mathrm{~g}$ for $1 \mathrm{~h}$ at $4^{\circ} \mathrm{C}$. One hundred $\mu \mathrm{g}$ of the TG-free infranatant was incubated with $25 \mathrm{nmol}\left[{ }^{3} \mathrm{H}-9,10\right]$-oleate labeled lipid droplet substrate and 5\% BSA in a total volume of $200 \mu \mathrm{l}$ for $1 \mathrm{~h}$ at $37^{\circ} \mathrm{C}$. The reaction was stopped by adding $3.25 \mathrm{ml}$ of methanol:chloroform:heptane (10:9:7) and $1 \mathrm{ml}$ of $0.1 \mathrm{M}$ potassium carbonate, and $0.1 \mathrm{M}$ boric acid ( $\mathrm{pH} 10.5$ ). After centrifugation, the radioactivity in $1 \mathrm{ml}$ of the upper phase was determined by scintillation counting.

\section{Measurements of lipids in peritoneal macrophages (PMs)}

Collected PMs were placed into $3 \mathrm{ml}$ of the mixture of chloroform and methanol [CHCl3: $\mathrm{MeOH}$ (2:1)]. The mixture was centrifuged at $2700 \mathrm{rpm}$ for $15 \mathrm{~min}$ at room temperature, and the lipid extract was transferred into a clean glass tube. The lipid extract was dried down under $\mathrm{N} 2$ stream on a heater at $60^{\circ} \mathrm{C}$ and resuspended in $3 \mathrm{ml}$ of the chloroform: methanol mixture before the phase separation by addition of $0.6 \mathrm{ml}$ of diluted $\mathrm{H} 2 \mathrm{SO} 4(0.05 \%)$. The sample tube was centrifuged at $2000 \mathrm{rpm}$ for $15 \mathrm{~min}$ at room temperature. The top aqueous phase and the middle protein phase were aspirated. The total volume of the bottom phase was recorded and $100 \mu$ of this solution was transferred to a new 16x100 mm screw cap tube containing $1 \mathrm{ml}$ of $1 \%$ Triton-X-100 in $\mathrm{CHCl} 3$. This mixture was dried down and dissolved in $0.5 \mathrm{ml}$ water for lipid measurements. Manufacturer's protocols were followed to measure the levels of triglycerides (Sigma \#T2449) and Free Fatty Acid (FFA, Sigma \#MAK044) in lipid extracts.

\section{Statistical analysis}

All data are presented as the mean \pm standard error of the mean (SEM). Differences between groups were evaluated for statistical significance using Student's $t$-tests or ANOVA. In each case, significance was defined as $P<0.05$.

\section{Results}

Macrophage CGI-58 inhibits inflammation

Currently, several studies have demonstrated that CGI-58 is involved in inflammatory responsiveness [12-14]. To address this event, CGI-58 was selectively overexpressed in macrophages in mice. Mice were fed a HFD for 18 weeks to elicit inflammatory responsiveness, since HFD is associated with a low-grade systemic inflammation [15]. In agreement with previous findings, we observed increased proinflammatory cytokine levels in plasma from HFD group compared with chow diet (CD) control (Fig. 1A). Furthermore, we also detected inhibited proinflammatory cytokine levels in the plasma of macrophage-specific CGI-58overexpressing transgenic mice fed a HFD compared to the parallel WT control (Fig. 1A). 


\section{Cellular Physiology Cell Physiol Biochem 2016;38:696-713 \begin{tabular}{ll|l} 
DOI: 10.1159/000443027 & (0) 2016 The Author(s). Published by S. Karger AG, Basel \\
and Biochemistry Published online: February 15, 2016 www.karger.com/cpb
\end{tabular} \\ Yang et al.: Macrophage CGI-58 Inhibits Inflammation}

To further confirm the role of macrophage CGI-58 in inflammation, we silenced CGI-58 expression in RAW264.7 cells and treated the cells with LPS. As expected, macrophage CGI58 deficiency aggravated LPS-induced inflammatory responsiveness by upregulating the expression levels of IL-1 $\beta$, IL-6, TNF $\alpha$, and MCP- 1 in CGI-58-silenced cells compared with control (Fig. 1B and C). Taken together, these results indicate that macrophage CGI-58 may suppress inflammatory responsiveness.

\section{Macrophage CGI-58 enhances the expression of PPAR $\alpha$ and PPAR $\gamma$}

PPAR family members are involved in modulating inflammation [8]. We therefore sought to determine whether CGI-58 affects the expression of PPAR family members, including PPAR $\alpha$, PPAR $\beta$, and PPAR $\gamma$. We isolated peritoneal macrophages from TG and WT mice, all of which were fed a HFD for 18 weeks, and examined the expression levels of PPAR family members. Interestingly, the mRNA and protein levels of PPAR $\alpha$ and PPAR $\gamma$ were significantly higher in the TG group than in WT control (Fig. 2A and B). Furthermore, silencing CGI-58 in RAW264.7 cells attenuated the mRNA and protein levels of PPAR $\alpha$ and PPAR $\gamma$ (Fig. 2C and D). However, we observed no obvious alteration to PPAR $\beta$ expression under either the CGI58-overexpressing or the CGI-58 knockdown condition (Fig. 2). These results suggest that macrophage CGI-58 may enhance the expression of PPAR $\alpha$ and PPAR $\gamma$.

\section{Macrophage CGI-58 promotes the PPAR $\gamma$ activity}

Since the expression of PPAR $\alpha$ and PPAR $\gamma$ was affected by CGI-58, we determined whether CGI-58 control the activities of PPARs. CGI-58 overexpression in macrophages promoted the PPAR $\gamma$ activity remarkably (Fig. 3A). As expected, silencing CGI-58 in

Fig. 1. Macrophage CGI-58 inhibits inflammation. (A) Mice were fed a chow diet (CD) or HFD for 18 weeks, and plasma concentrations of cytokines were detected using an ELISA kit ( $\mathrm{n}=6$, means \pm SEM). ${ }^{*} P<0.05$ vs. WT/CD mice; ${ }^{\#} P<0.05$ vs. WT/HFD mice. WT, wild type mice; TG, macrophage-specific CGI-58 transgenic mice. (B) RAW264.7 cells were transfected with NT siRNA or si-CGI-58. After 48 hours, cells were treated with LPS (100 ng/ $\mathrm{ml}$ ) for 6 hours. The mRNA levels of proinflammatory cytokines (top; $\mathrm{n}=3$, means \pm SEM) and their concentrations in the supernatant (conditioned culture medium) (bottom; $\mathrm{n}=5$, means \pm SEM) were determined. $* P<0.05$ vs. si-NT control. si-NT, non-targeting siRNA; si-CGI-58, CGI-58 siRNA.
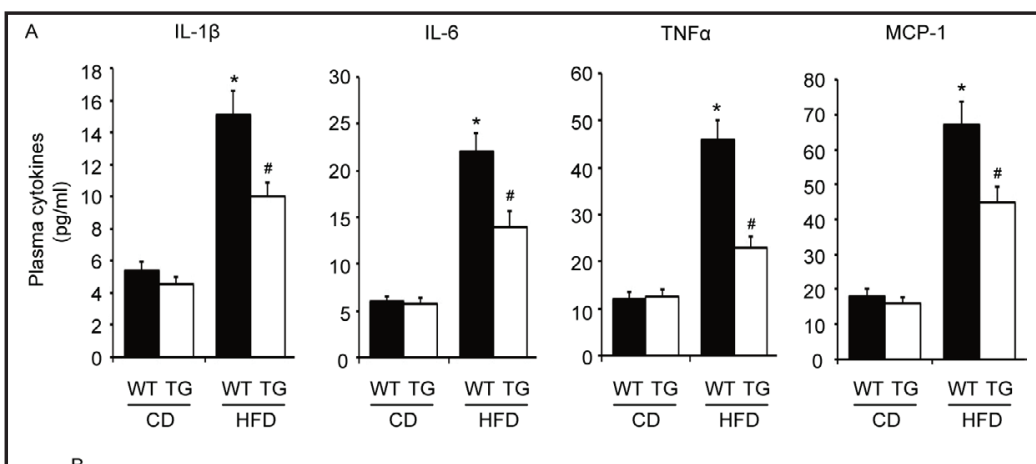

B
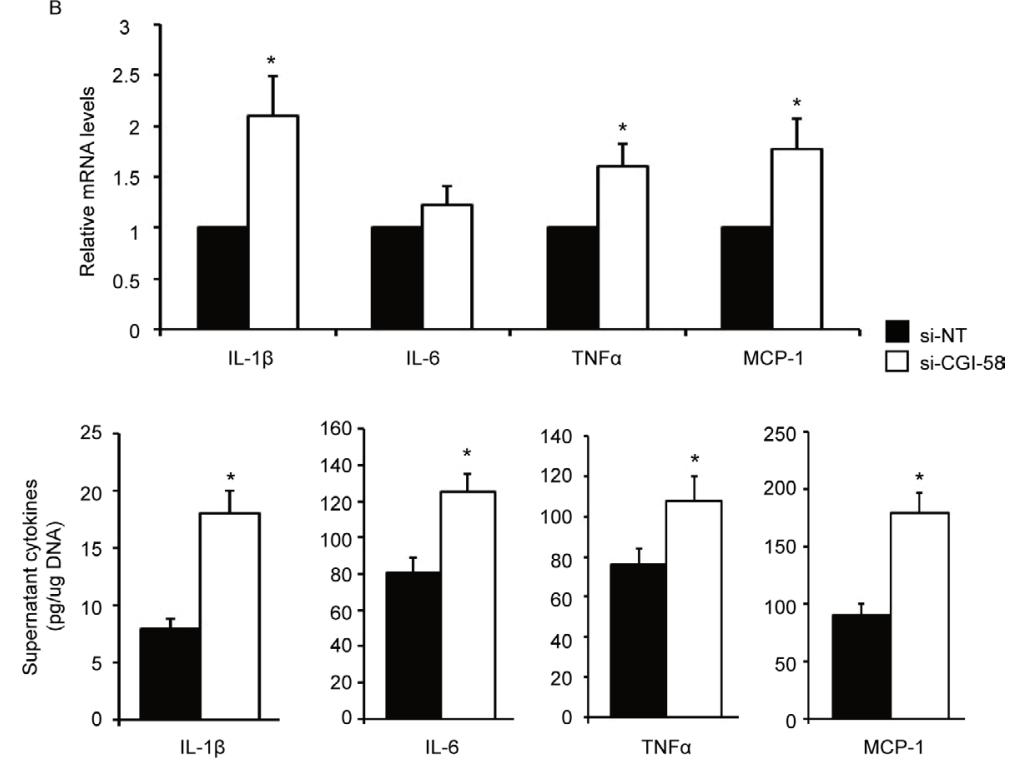


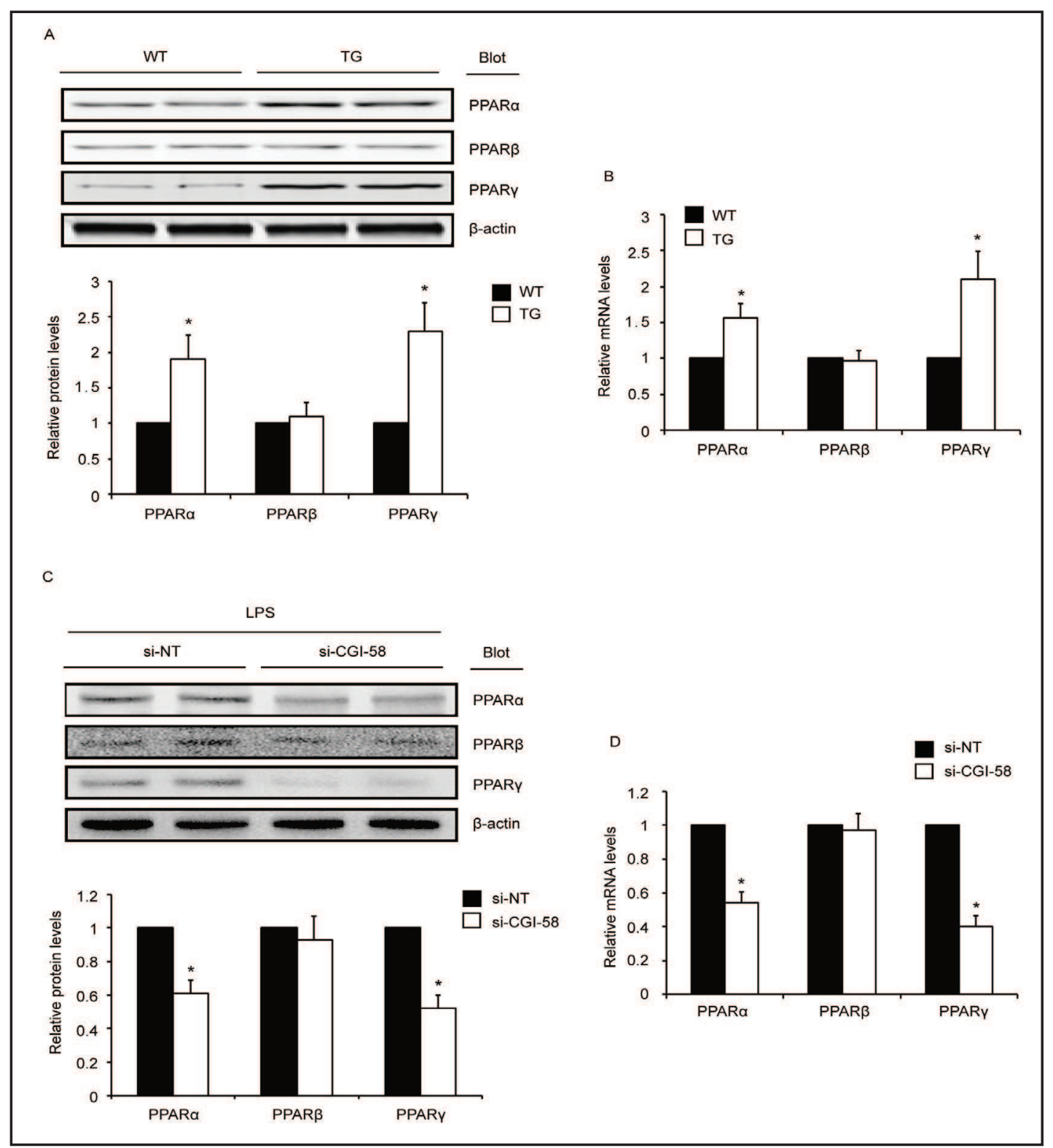

Fig. 2. Macrophage CGI-58 enhances the expression of PPAR $\alpha$ and PPAR $\gamma$. (A and B) Mice were fed a HFD for 18 weeks, and then peritoneal macrophages were isolated. The cellular protein levels of PPAR $\alpha$, PPAR $\beta$, and PPAR $\gamma$ were detected using immunoblotting analysis $(n=4$, means $\pm S E M)$, and the relative mRNA levels were detected using real-time PCR $\left(n=5\right.$, means \pm SEM). ${ }^{*} P<0.05$ vs. WT control mice. WT, wild type mice; TG, macrophage-specific CGI-58 transgenic mice. (C and D) RAW264.7 cells were transfected with NT siRNA or si-CGI-58. After 48 hours, cells were treated with LPS $(100 \mathrm{ng} / \mathrm{ml})$ for 6 hours. The cellular protein and mRNA levels of PPAR $\alpha$, PPAR $\beta$, and PPAR $\gamma$ were determined as in A and B ( $n=4$, means \pm SEM). ${ }^{*} P<0.05$ vs. si-NT control. si-NT, non-targeting siRNA; si-CGI-58, CGI-58 siRNA.

macrophages manifested opposite results on PPAR $\gamma$ (Fig. 3B). However the activities of PPAR $\alpha$ and PPAR $\beta$ were unaffected (Fig. 3A and B). Furthermore, a luciferase assay was performed to evaluate the activity of PPAR $\gamma$ binding to PPAR-responsive element (PPRE). As shown in Fig. 3C, CGI-58 promoted the binding capacity of PPAR $\gamma$ to PPRE in a dosedependent manner. Therefore, these results indicated that macrophage CGI-58 may promote the functional activity of PPAR $\gamma$. 


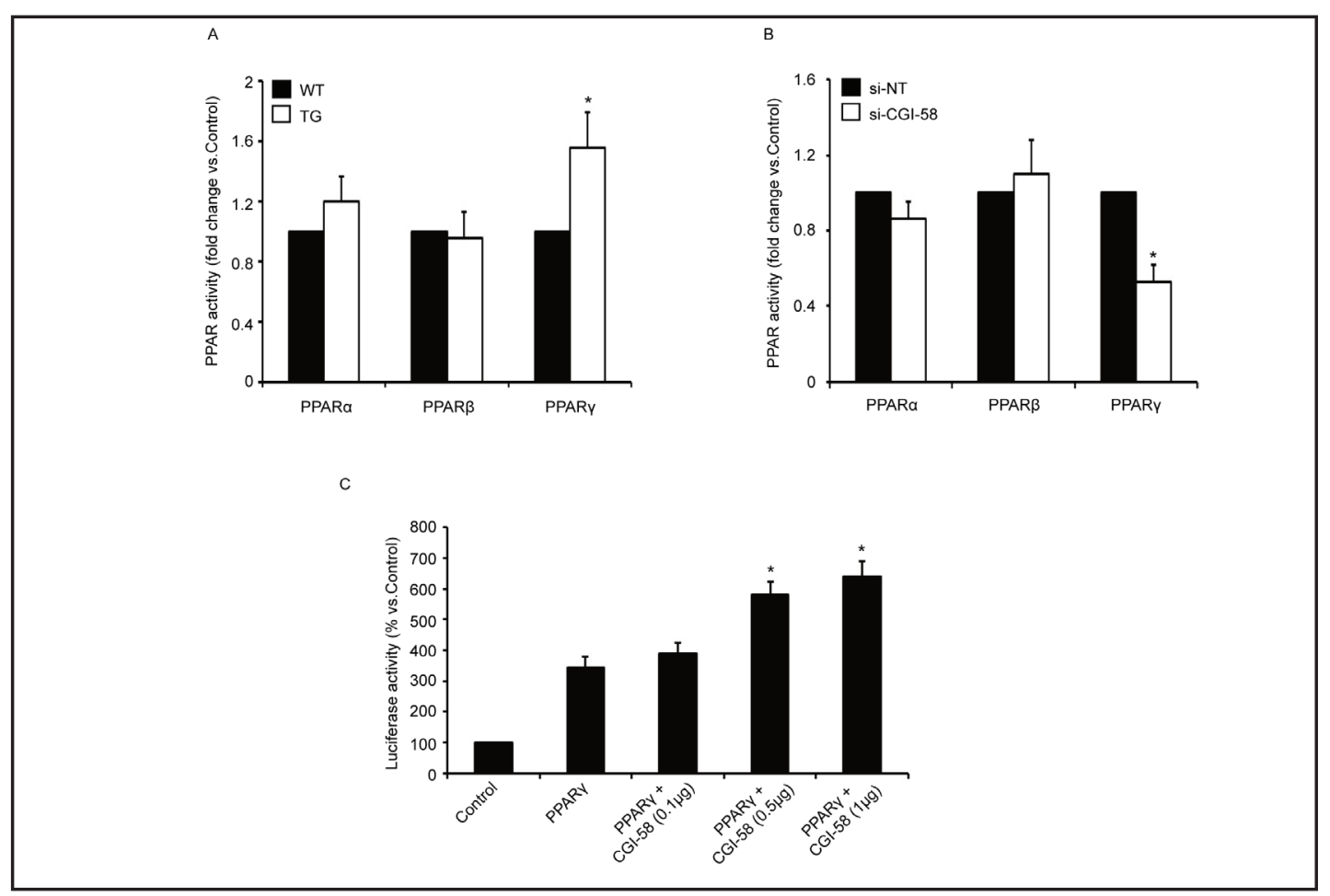

Fig. 3. CGI-58 enhances PPAR $\gamma$ activity. (A) Mice were fed a HFD for 18 weeks, and then peritoneal macrophages were isolated. PPAR activities were determined. The values were expressed as fold change relative to controls $\left(\mathrm{n}=3\right.$, means \pm SEM). ${ }^{*} P<0.05$ vs. WT control mice. WT, wild type mice; TG, macrophage-specific CGI-58 transgenic mice. (B) RAW264.7 cells were transfected with NT siRNA or si-CGI-58. After 48 hours, cells were treated with LPS $(100 \mathrm{ng} / \mathrm{ml})$ for 6 hours. The PPAR activities were determined as in A ( $\mathrm{n}=3$, means \pm SEM). ${ }^{*} P<0.05$ vs. si-NT control. si-NT, non-targeting siRNA; si-CGI-58, CGI-58 siRNA. (C) 293T cells were transfected with a reporter plasmid coding for firefly luciferase under transcriptional control of PPAR $\gamma$-responsive elements, a plasmid coding for Renilla luciferase (transfection control), and a single plasmid or a mixture of plasmids coding for PPAR $\gamma$ and CGI-58. 24 hours after infection, cells were harvested and luciferase activity was measured $\left(n=3\right.$, means \pm SEM). ${ }^{*} P<0.05$ vs. PPAR $\gamma$ alone group.

CGI-58 suppresses macrophage inflammation via PPAR signaling

Because CGI-58 induced changes in the expression of PPAR $\alpha$ and PPAR $\gamma$ in macrophages, we hypothesized that the role of CGI-58 in inflammation was mediated by PPAR $\alpha$ or PPAR $\gamma$ signaling. To address this question, CGI-58 knockdown RAW264.7 cells were pretreated with the PPAR $\gamma$-specific agonist rosiglitazone. LPS-induced inflammatory responsiveness was exacerbated by CGI-58 silencing, and this CGI-58 deficiency-induced enhancement of inflammation was markedly attenuated by rosiglitazone. Observed events included effects on the levels of the proinflammatory cytokines IL-1 $\beta$, IL-6, TNF $\alpha$, and MCP-1 (Fig. 4A). However, the PPAR $\alpha$ agonist fenofibrate affected only IL- 6 , and did not have an obvious impact on the supernatant levels of IL-1 $\beta$, TNF $\alpha$, or MCP- 1 (data not shown). To further confirm the role of PPAR $\gamma$ in the modulation of CGI-58-mediated inflammation, PPAR $\gamma$ expression was silenced in peritoneal macrophages from WT and TG mice, and inflammatory responsiveness was assayed. Compared with the WT control group, the TG group showed lower inflammatory responsiveness. However, the suppressed inflammation in the TG group was significantly abolished by PPAR $\gamma$ silencing (Fig. 4B). Taken together the results that CGI-58 promoting PPAR expression and activity, we speculated that the regulatory role of CGI-58 in inflammation may mainly involve the PPAR $\gamma$ signaling. 


\section{Cellular Physiology Cell Physiol Biochem 2016;38:696-713 \begin{tabular}{ll|l} 
DOI: 10.1159/000443027 & $\begin{array}{l}\text { O 2016 The Author(s). Published by S. Karger AG, Basel } \\
\text { www.karger.com/cpb }\end{array}$ \\
\hline
\end{tabular}

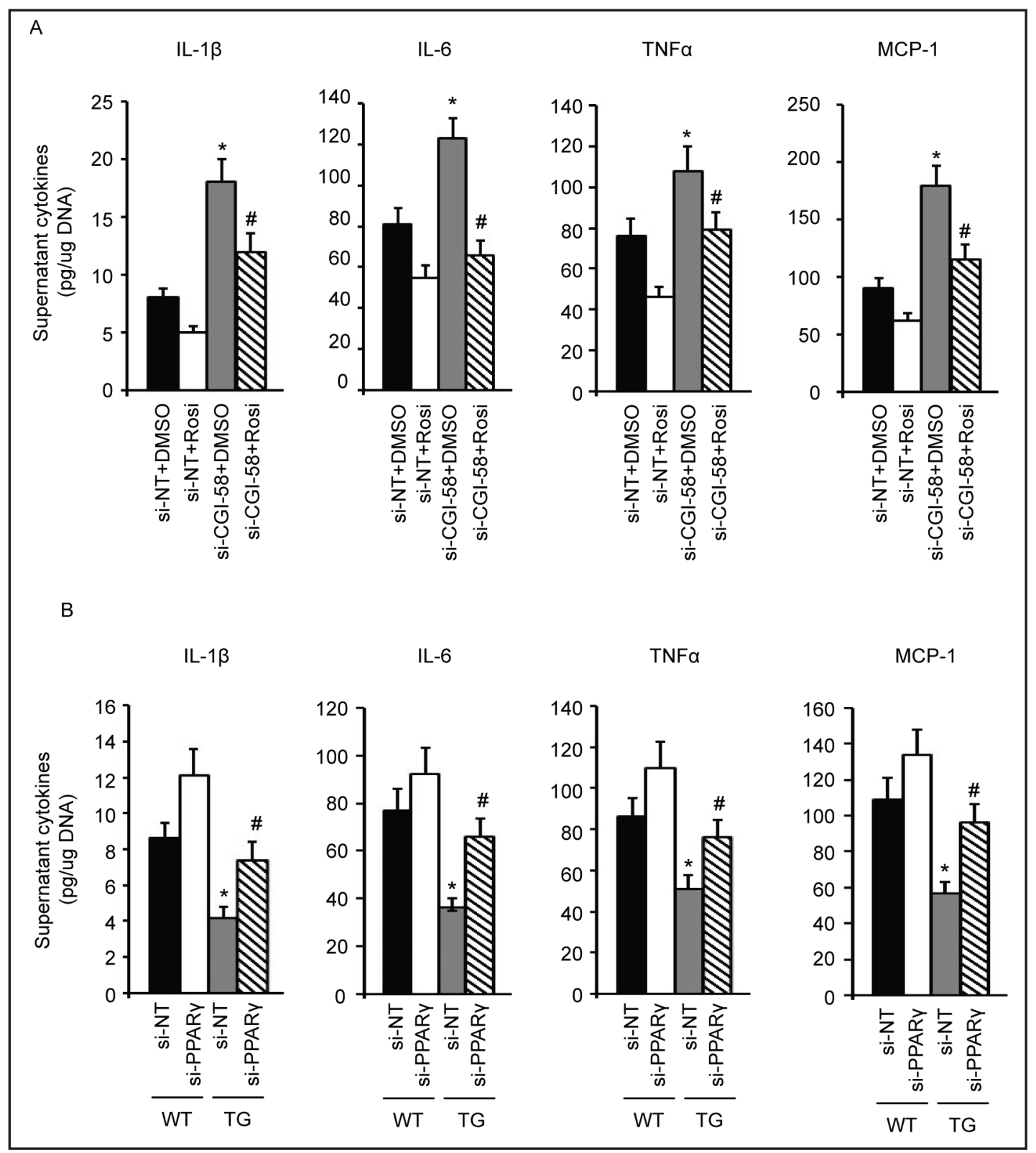

Fig. 4. CGI-58 suppresses macrophage inflammation through PPAR $\gamma$ signaling. (A) RAW264.7 cells were transfected with NT siRNA or si-CGI-58. After 48 hours, cells were pretreated with $50 \mathrm{nM}$ rosiglitazone (Rosi) or vehicle DMSO for 30 minutes and then treated with LPS (100 ng/ml) for 6 hours. The proinflammatory cytokine concentrations in the supernatants (conditional culture medium) were determined ( $\mathrm{n}=5$, means \pm SEM). ${ }^{*} P<0.05$ vs. parallel si-NT control. $P<0.05$ vs. parallel DMSO control. si-NT, non-targeting siRNA; si-CGI-58, CGI-58 siRNA. (B) Peritoneal macrophages were isolated from mice and cultured. The cells were transfected with NT siRNA or si-PPAR $\gamma$. After 48 hours, cells were treated with LPS $(100 \mathrm{ng} / \mathrm{ml})$ for 6 hours. The proinflammatory cytokine concentrations in the supernatants ( $n=5$, means \pm SEM) were determined. ${ }^{*} P<0.05$ vs. WT/si-NT control. ${ }^{*} P<0.05$ vs. TG/si-NT control. WT, wild type mice; TG, macrophage-specific CGI-58 transgenic mice; si-NT, non-targeting siRNA; si- PPAR $\gamma$, PPAR $\gamma$ siRNA.

\section{Macrophage CGI-58 inhibits ROS overproduction and mitochondrial dysfunction}

Oxidative stress and mitochondrial biogenesis are related to inflammatory processes. We therefore examined whether macrophage CGI-58 impacted cellular ROS production and mitochondrial function. As shown in Fig. 5A, ROS production was significantly suppressed 


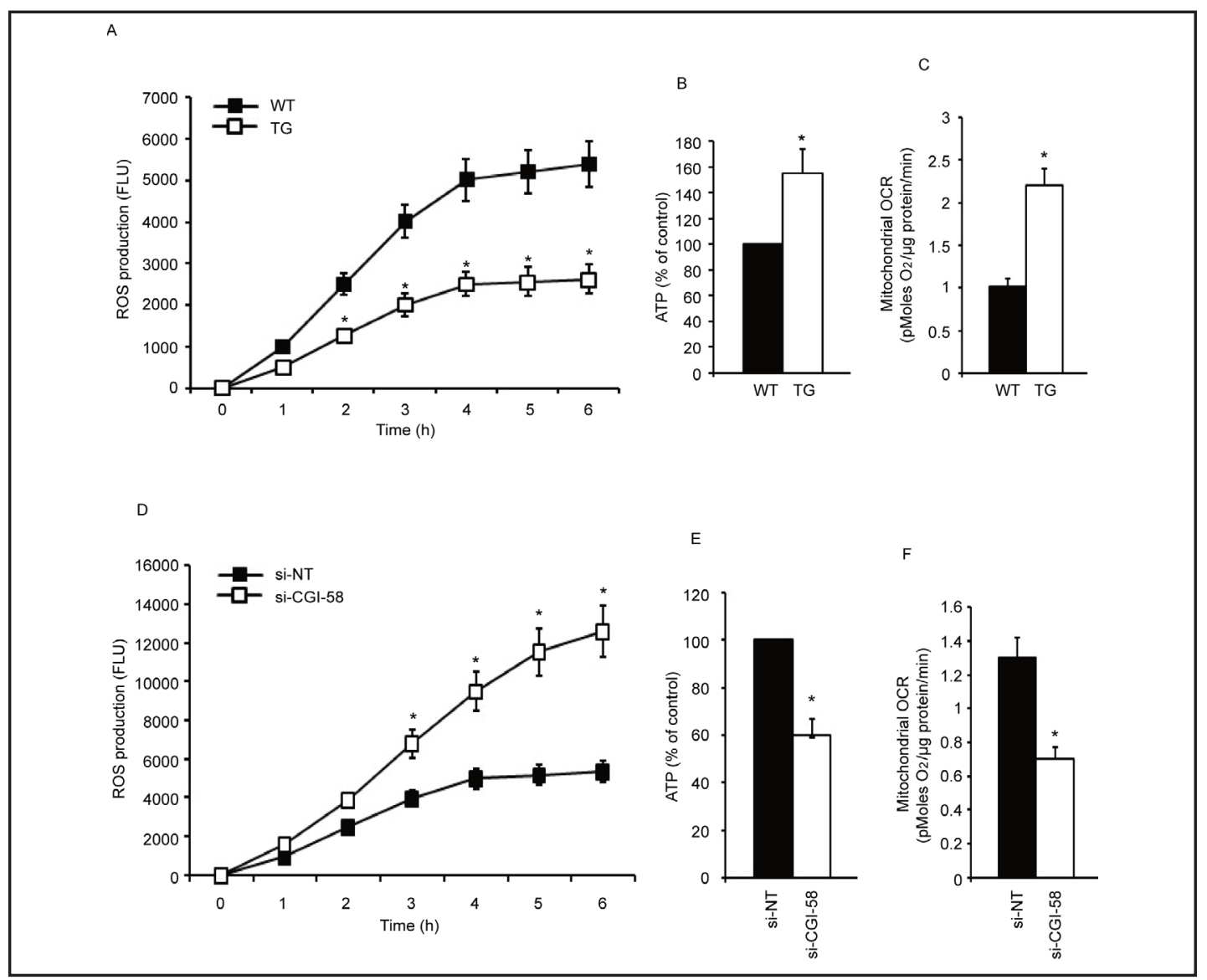

Fig. 5. Macrophage CGI-58 inhibits ROS overproduction and mitochondrial dysfunction. (A, B, and C) Peritoneal macrophages were isolated from mice and cultured. The cells were treated with LPS (100 ng/ml) for the indicated times or for 6 hours. Cellular ROS production, ATP levels, and mitochondrial oxygen consumption rates (OCRs) were determined as described in the Methods section ( $\mathrm{n}=5$, means $\pm \mathrm{SEM}) . * P<0.05$ vs. WT control mice. WT, wild type mice; TG, macrophage-specific CGI-58 transgenic mice. (D, E, and F) RAW264.7 cells were transfected with NT siRNA or si-CGI-58. After 48 hours, cells were treated with LPS $(100 \mathrm{ng} / \mathrm{ml})$ for the indicated times or for 6 hours. Cellular ROS production, ATP levels, and mitochondrial OCRs were determined as described in the Methods section $(\mathrm{n}=4$, means $\pm \mathrm{SEM}) .{ }^{*} P<0.05$ vs. si-NT control. si-NT, non-targeting siRNA; si-CGI-58, CGI-58 siRNA.

in the TG group compared with the WT control group. Furthermore, macrophage CGI-58 overexpression enhanced mitochondrial ATP biogenesis and oxygen consumption rates (OCRs) (Fig. 5B and C). However, CGI-58 knockdown in macrophages exacerbated ROS production (Fig. 5D) and suppressed mitochondrial ATP biogenesis and OCRs (Fig. 5E and F). These results therefore indicate that macrophage CGI-58 may modulate cellular ROS production and mitochondrial function under inflammatory conditions.

CGI-58 suppresses ROS overproduction and mitochondrial dysfunction via PPAR $\gamma$ signaling

Because PPAR $\gamma$ was involved in CGI-58-mediated inflammatory modulation, we next explored the role of PPAR $\gamma$ in ROS production and mitochondrial function. Pretreatment of RAW264.7 cells with rosiglitazone inhibited CGI-58 deficiency-induced ROS overproduction (Fig. 6A). In addition, the decreases in mitochondrial ATP biogenesis and OCRs that were induced by CGI-58 deficiency were substantially reversed by rosiglitazone (Fig. 6B and C). Furthermore, PPAR $\gamma$ silencing largely impaired CGI-58 overexpression-induced suppression of ROS overproduction (Fig. 6D) and mitochondrial dysfunction (Fig. 6E and F). Collectively, 


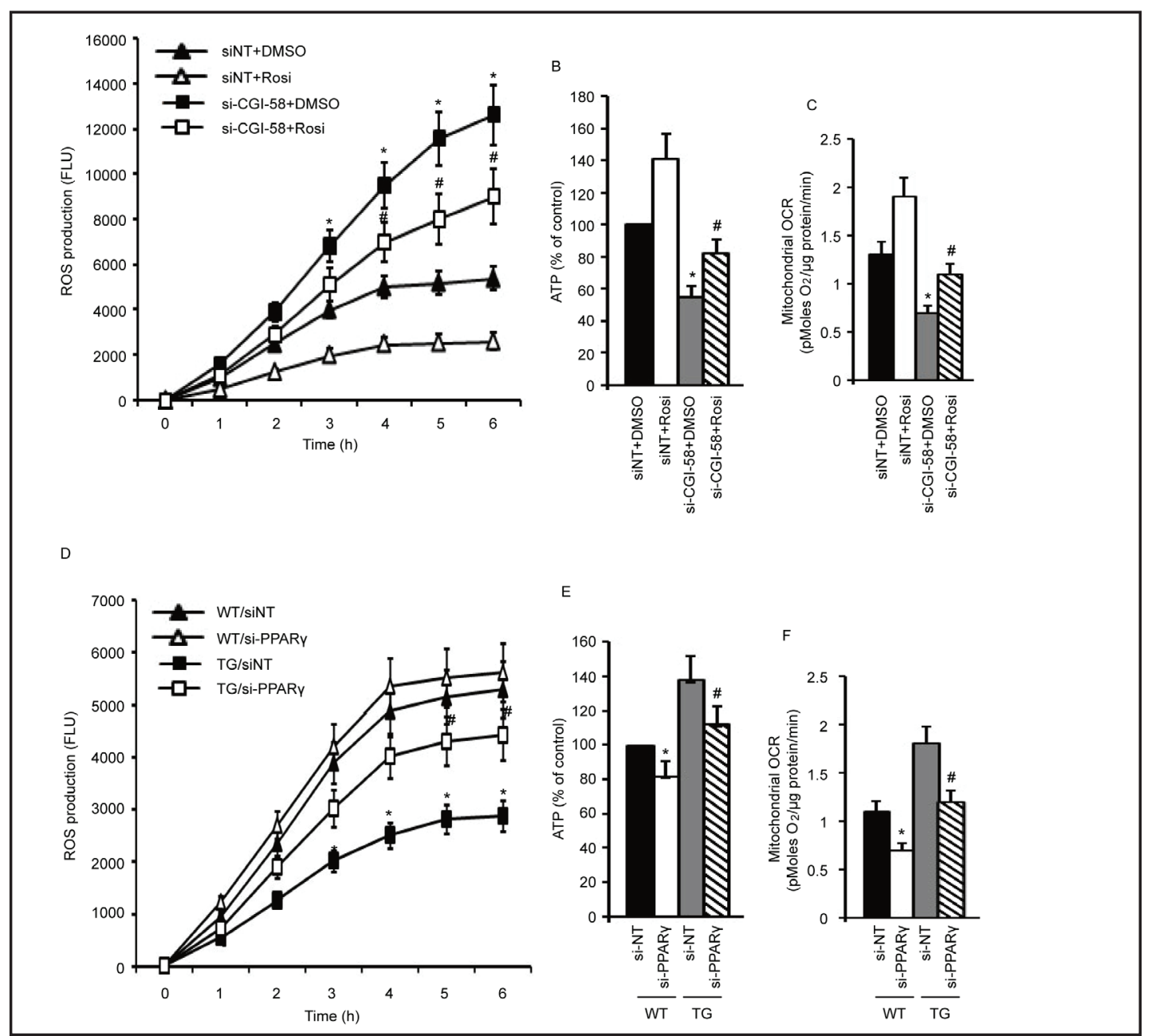

Fig. 6. Macrophage CGI-58 suppresses ROS overproduction and mitochondrial dysfunction through PPAR $\gamma$ signaling. (A, B, and C) RAW264.7 cells were transfected with NT siRNA or si-CGI-58. After 48 hours, cells were pretreated with $50 \mathrm{nM}$ rosiglitazone (Rosi) or vehicle DMSO for 30 minutes and then treated with LPS $(100 \mathrm{ng} / \mathrm{ml})$ for the indicated times or for 6 hours. Cellular ROS production, ATP levels, and mitochondrial OCRs were determined as described in the Methods section $\left(n=4\right.$, means \pm SEM). ${ }^{*} P<0.05$ vs. parallel si-NT control. " $P<0.05$ vs. parallel DMSO control. si-NT, non-targeting siRNA; si-CGI-58, CGI-58 siRNA. (D, E, and F) Peritoneal macrophages were from mice isolated and cultured. The cells were transfected with NT siRNA or si-PPAR $\gamma$. After 48 hours, cells were treated with LPS (100 ng/ml) for 6 hours. Cellular ROS production, ATP levels, and mitochondrial OCRs were determined $\left(\mathrm{n}=5\right.$, means \pm SEM). ${ }^{*} P<0.05$ vs. WT $/$ si-NT control. ${ }^{\#} P<0.05$ vs. TG/si-NT control. WT, wild type mice; TG, macrophage-specific CGI-58 transgenic mice; si-NT, non-targeting siRNA; si-PPAR $\gamma, \operatorname{PPAR} \gamma$ siRNA.

these results indicate that PPAR $\gamma$ signaling may be associated with the regulatory role of CGI-58 in ROS production and mitochondrial function.

\section{Macrophage CGI-58 promotes PPAR expression by inhibiting HDAC2 binding to the PPAR promoter}

Histone acetylation modification modulates gene transcription by affecting chromatin remodeling. HDACs catalyze the removal of acetyl groups from histones, which leads to transcriptional repression. Here, we studied whether the CGI-58-mediated upregulation of PPAR $y$ expression was caused by histone acetylation and the removal of HDACs from the PPARY promoter. First, we noticed that global HDAC activity was decreased and increased in the macrophages with CGI-58 overexpression and knockdown, respectively (Fig. 7A). 


\section{Cellular Physiology \\ Cell Physiol Biochem 2016;38:696-713 \\ \begin{tabular}{ll|l} 
and Biochemistry Published online: February 15, 2016 & 2016 Tww.karger.com/cph \\
wwhor(s)
\end{tabular}}

Yang et al.: Macrophage CGI-58 Inhibits Inflammation

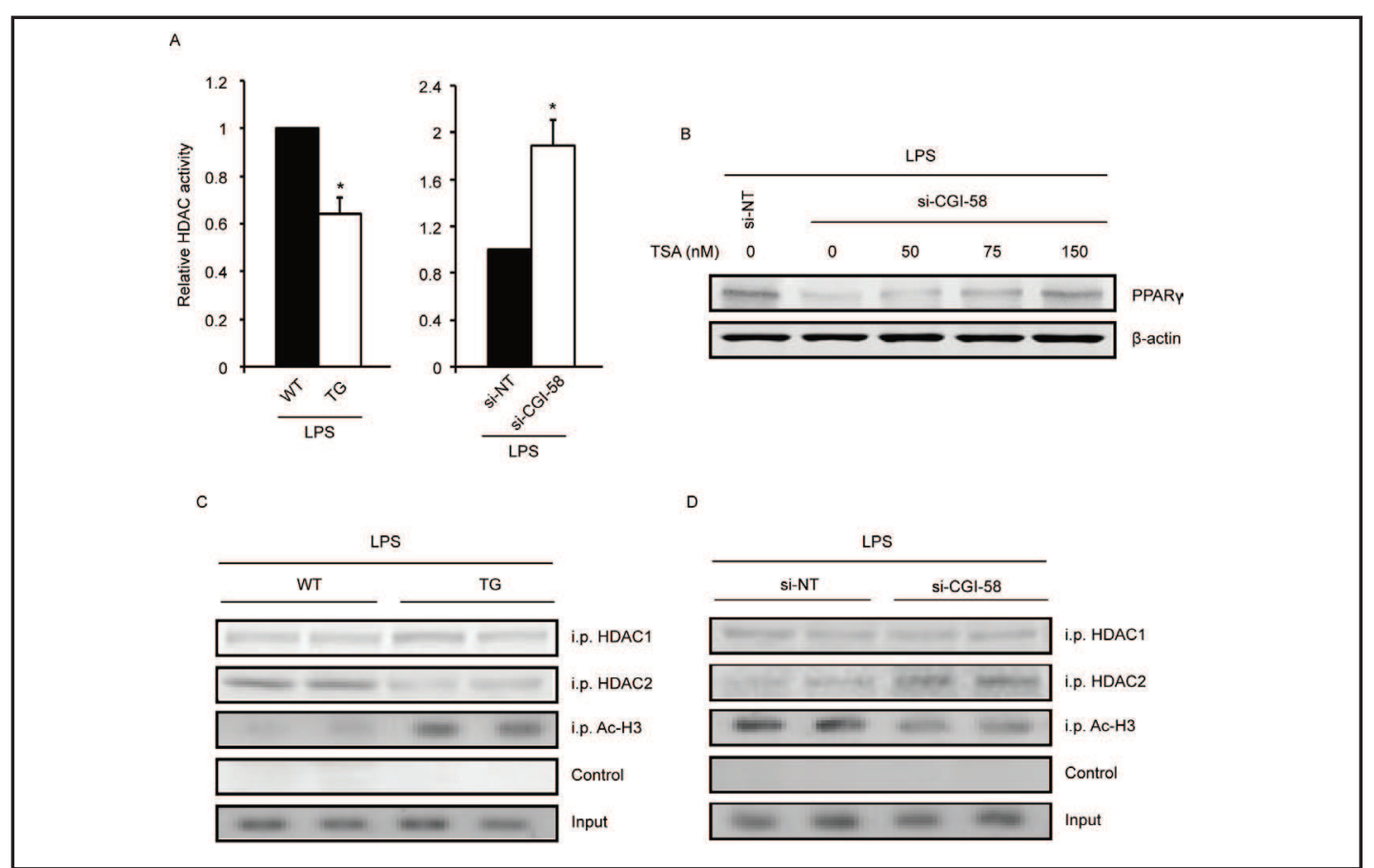

Fig. 7. Macrophage CGI-58 enhances the expression of PPAR $\gamma$ by affecting histone acetylation at the PPAR promoter. (A) Peritoneal macrophages were isolated from mice and cultured. Then, the cells were treated with LPS (100 ng/ml) for 6 hours (Left). RAW264.7 cells were transfected with NT siRNA or si-CGI-58. After 48 hours, cells were treated with LPS (100 ng/ml) for 6 hours (Right). HDAC enzyme activity was assayed ( $\mathrm{n}=3$, means \pm SEM). ${ }^{*} P<0.05$ vs. parallel control. (B) RAW264.7 cells were transfected with NT siRNA or si-CGI-58. After 48 hours, cells were pretreated with various concentrations of TSA for 30 minutes and then treated with LPS $(100 \mathrm{ng} / \mathrm{ml})$ for 6 hours. The cellular PPAR $\gamma$ protein level was detected using immunoblotting analysis $(n=3$, means \pm SEM). (C) Peritoneal macrophages were isolated from mice and cultured. Then, the cells were treated with LPS $(100 \mathrm{ng} / \mathrm{ml})$ for 6 hours. A ChIP assay was performed with antibodies to Ac-H3, HDAC1 or HDAC2 (see Methods section). The data in the figure are representative of three separate experiments. (D) RAW264.7 cells were transfected with NT siRNA or si-CGI-58. After 48 hours, cells were then treated with LPS $(100 \mathrm{ng} / \mathrm{ml})$ for 6 hours. A ChIP assay was performed. The data in the figure are representative of three separate experiments. WT, wild type mice; TG, macrophage-specific CGI-58 transgenic mice; si-NT, non-targeting siRNA; si-CGI-58, CGI-58 siRNA.

The HDAC inhibitor trichostatin (TSA) significantly limited the loss of PPAR $\gamma$ expression observed in CGI-58-silenced macrophages in a dose-dependent manner (Fig. 7B). These results suggested that HDACs may play roles in the CGI-58-mediated regulation of PPAR $\gamma$ expression. Thus, we next determined whether the binding of HDACs to the PPAR $\gamma$ promoter was changed. ChIP assays showed that overexpression and knockdown of CGI-58 decreased and increased, respectively, the recruitment of HDAC2 to the PPAR $\gamma$ promoter (Fig. 7C and D). However, we detected only a slight alteration in the binding of HDAC1 to the PPAR $\gamma$ promoter (Fig. 7C and D). Additionally, acetylated histone H3 (Ac-H3) was regulated in an opposite manner compared to HDAC2 (Fig. 7C and D). Overall, these findings indicate that the induction of PPAR $\gamma$ expression by CGI-58 is associated with histone acetylation and the removal of HDAC2 from the PPAR $\gamma$ promoter.

Macrophage ATGL does not impact inflammation and CGI-58-induced PPAR signaling

It has been shown that CGI-58 promotes intracellular fat breakdown by activating the triglyceride hydrolase activity of ATGL. To determine whether ATGL has a similar effect on macrophage inflammation, we silenced ATGL expression in RAW264.7 cells. Unfortunately, we did not observe a significant difference in the levels of the proinflammatory cytokines 


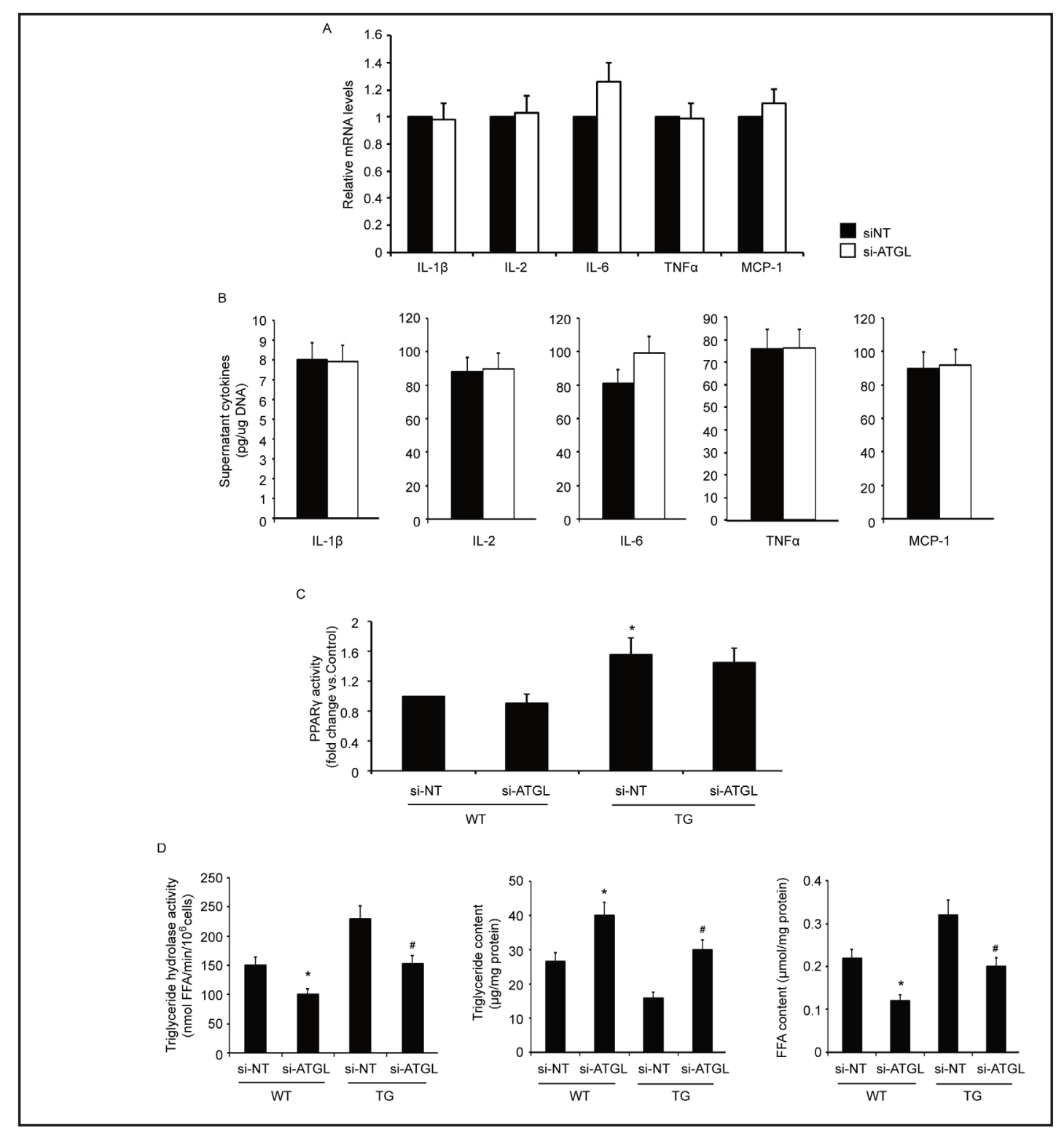

Fig. 8. Macrophage ATGL silencing does not affect inflammatory responsiveness. (A) RAW264.7 cells were transfected with NT siRNA or si-ATGL. After 48 hours, cells were then treated with LPS (100 ng/ml) for 6 hours. The mRNA levels of proinflammatory cytokines were determined ( $n=3$, means \pm SEM). (B) Cells were treated as in A. The proinflammatory cytokine concentrations were detected in the supernatants (conditional culture medium) ( $\mathrm{n}=3$, means \pm SEM). (C) Peritoneal macrophages were collected from WT or TG mice fed a HFD for 18 weeks. Cells were transfected with NT siRNA or si-ATGL. After 48 hours, PPAR $\gamma$ activity was detected $(\mathrm{n}=3$, means \pm SEM). $* P<0.05$ vs. WT/si-NT control. (D) Cells were collected and transfeced as in C. Triglyceride hydrolase activity and triglyceride and FFA contents were detected $(\mathrm{n}=3$, means \pm SEM). ${ }^{*} P<0.05$ vs. WT/si-NT control. si-NT, non-targeting siRNA; si-ATGL, ATGL siRNA; WT, wild type mice; TG, macrophage-specific CGI-58 transgenic mice; FFA, free fatty acid.

IL-1 $\beta$, IL-6, TNF $\alpha$, or MCP-1 between the ATGL knockdown and control groups (Fig. 8A and B). We observed a small change in IL-6 expression, but it was not statistically significant. Moreover, we also silenced ATGL expression in macrophages from WT and TG mice. Although ATGL deficiency inhibited triglyceride hydrolase activity and triglyceride and free fatty acid concentrations (Fig. 8D), it showed no significant effect on PPAR $\gamma$ activity statistically (Fig. 


\section{Cellular Physiology Cell Physiol Biochem 2016;38:696-713 \\ \begin{tabular}{ll|l} 
and Biochemistry Published online: February 15, 2016 & $\begin{array}{l}\text { () 2016 The Author(s). Published by S. Karger AG, Basel } \\
\text { www.karger.com/cpb }\end{array}$ \\
\hline
\end{tabular}}

Yang et al.: Macrophage CGI-58 Inhibits Inflammation

3C). Therefore, these results indicate that CGI-58 suppresses inflammation and increases PPAR $\gamma$ signaling improbably through promoting ATGL activity.

\section{Discussion}

In this study, we demonstrated that CGI-58, a lipolytic factor, is an endogenous suppressor of inflammatory responsiveness in macrophages. We showed that CGI-58 promoted PPAR $\gamma$ expression and activity, which was responsible for the suppression of mitochondrial dysfunction and inflammation.

CGI-58 promotes cellular triglyceride hydrolysis and fat breakd own by coactivating ATGL [2]. However, mutations in these two proteins cause distinct phenotypes [16-19]. Recent studies of mice deficient in CGI-58 have clearly shown that ATGL-independent functions for CGI-58 must also exist, at least in some tissues and cell types [18, 20]. Besides adipocytes and fatty tissues, CGI-58 is expressed in many other cells or tissues including brain, pancreas, macrophages, testis, lung, kidney, and stomach; however, its functional role in these tissues has not been fully elucidated [21-24]. To date, several studies have demonstrated the causal link between CGI-58 and inflammation [12-14]. Currently, in our investigation, overexpression of CGI-58 in macrophages inhibited plasma proinflammatory cytokines. In contrast, CGI58 deficiency aggravated inflammatory responsiveness in macrophages (Fig. 1). Therefore, macrophage CGI-58 may be a novel mediator that suppresses inflammation. However, there are few studies to address the underlying mechanisms responsible for the anti-inflammatory effect of CGI-58. Lord et al. demonstrated that CGI-58 drove generation of signaling lipids directly or indirectly to generate lipid signals, which act as a critical second messenger to impact inflammatory responsiveness [12]. Moreover, CGI-58 deficiency triggered SOCS3/ FOXO1pathway to induce a vicious cycle that amplifies IL-1 $\beta$ secretion in macrophages [14]. As a coactivator of ATGL, perhaps the modulatory role of CGI-58 in inflammation may be through ATGL. Although we observed significant decrease in lipolysis by ATGL deficiency (Fig. 8D), ATGL knockdown macrophages did not display an anti-inflammatory or proinflammatory phenotype (Fig. 8A and B). Interestingly, a study by Aflaki et al. indicated that IL-6 level was decreased in ATGL-deficient macrophages, accompanied by impaired macrophage [25]. Maybe the link between ATGL and inflammation is complex and depend on metabolic pathway and inducement factors involved. Despite these significant findings, the underlying molecular mechanisms involved in CGI-58's anti-inflammatory functions still need to be fully elucidated.

PPARs are ligand-activated transcription factors that belong to the nuclear receptor superfamily. PPARs are activated by fatty acid or its derivatives and control the expression of an array of genes involved in lipid metabolism, inflammation, and development [2628]. The binding of PPARs to DNA is in a sequence-specific manner. An important function of PPARs is the negative regulation of inflammatory gene expression in a signal-specific manner through a mechanism termed "transrepression" [29]. NF- $\kappa$ B and AP-1 are key inflammatory transcription factors, and binding sites for these proteins have described in many immediate inflammatory response genes. On inactive promoters, factors such as $\mathrm{NF}-\mathrm{\kappa B}$ are bound to $\mathrm{N}-\mathrm{CoR}$ corepressor complexes, maintaining basal repression. During transrepression, activated PPARs prevent NCoR from being cleared from the promoters of inflammatory genes [30]. Macrophages express PPAR $\alpha$, PPAR $\beta$, and PPAR $\gamma$. PPAR $\alpha$ is a major regulator of the mitochondrial and peroxisomal $\beta$-oxidation pathways, which are involved in the pathogenesis of various liver complications [28]. PPAR $\alpha$ ligands negatively regulate $I L-6$ promoter activation and IL-6-induced atherosclerosis [31]. Moreover, the absence of PPAR $\alpha$ expression is suggested to prolong inflammatory responsiveness [31]. In our study, CGI-58 promoted PPAR $\alpha$ mRNA and protein levels in macrophages (Fig. 2). However, CGI-58 failed to affect its activity (Fig. 3A). Furthermore, PPAR $\alpha$ agonist had no significant influence on CGI-58 deficiency-induced aggravation of inflammation, except for an effect on IL-6 (data not shown). Activation of PPAR $\beta$ has been shown to improve insulin resistance and to exhibit 


\section{Cellular Physiology Cell Physiol Biochem 2016;38:696-713 and Biochemistry Published online: February 15, 2016 www.karger.com/cpb}

Yang et al.: Macrophage CGI-58 Inhibits Inflammation

anti-inflammatory properties in the vessel wall [32]. However, CGI-58 had no effect on PPAR $\beta$ expression and activity in our study (Fig. 2 and 3A). PPAR $\gamma$ was widely recognized as an anti-inflammatory agent. PPAR $\gamma$ activation inhibits adhesion cascades and is detrimental to vascular inflammatory events [33]. Furthermore, PPAR $\gamma$ is now considered as important determinant of macrophage polarization [34], migration [35], and differentiation [36]. Currently, our data showed that CGI-58 promoted PPAR $\gamma$ expression (Fig. 2) and activity (Fig. 3) in macrophages. Furthermore, a PPAR $\gamma$ agonist markedly attenuated the CGI-58 deficiency-induced aggravation of inflammation (Fig. 4A). In addition, PPAR $\gamma$ knockdown largely abolished the anti-inflammatory function of CGI-58 (Fig. 4B). Taken together, these results led us to hypothesize that the anti-inflammatory function of CGI-58 might operate mainly through PPAR $\gamma$ signaling.

ROS play critical roles in inflammatory progress. Mitochondria are the major source of cellular oxidative stress, and mitochondrial dysfunction has the potential to raise cellular ROS [9]. Currently, several studies have addressed the correlation between CGI58 and oxidative stress $[13,37]$. Goeritzer et al. demonstrated that CGI-58 deficiency in macrophages decreased mitochondrial respiration [37]. In agreement with this finding, our study showed that overexpression and knockdown of CGI-58 inhibited and increased, respectively, macrophage oxidative stress and mitochondrial dysfunction (Fig. 5). These data suggest that CGI-58 is biologically involved in maintaining mitochondrial homeostasis. It has been shown that PPARs play critical roles in mitochondrial biogenesis and function [38]. In our study, a PPAR $\gamma$ agonist inhibited the ROS overproduction and mitochondrial dysfunction that were induced by CGI-58 deficiency (Fig. 6A). Moreover, PPAR $\gamma$ knockdown substantially abolished the CGI-58 overexpression-induced suppression of ROS overproduction and mitochondrial dysfunction (Fig. 6B). Therefore, these findings strongly indicate that the role of CGI-58 in suppression of ROS overproduction and mitochondrial dysfunction may be mediated by PPAR $\gamma$. However, in the context of our study, CGI-58 may promote lypolytic process by activating ATGL, resulting in increased fatty acid (FA) availability. Therefore, it is possible that, due to adaptation to elevated levels of FAs, oxygen consumption rate and ATP biogenesis increased. Further study is needed to verify this possibility.

In the current study, we provide evidence that CGI-58 dampened inflammatory responsiveness and PPAR $\gamma$ signaling was involved in this process. Here, it is unclear which mechanisms responsible for the events that CGI-58 promotes PPAR $\gamma$ signaling. As a coactivator of ATGL, CGI-58 affects intracellular fat breakdown and therefore release of FAs from ATGL pathway. In skeletal muscle CGI-58 controlled oxidative metabolism by modulating FA availability and the activation of PPAR $\delta$ [39]. Perhaps the causal link between CGI-58 and PPAR $\gamma$ is due to FA availability controlled by CGI-58 and ATGL. However, unlike CGI-58-induced PPAR $\gamma$ signaling and anti-inflammatory property, we did not observe significant inflammatory changes by ATGL silencing (Fig. 8A and B). Moreover, ATGL knockdown showed no significant effect on PPAR $\gamma$ activity in macrophages from TG mice (Fig. 8C), indicating that CGI-58 increases PPAR $\gamma$ signaling improbably simply through promoting ATGL activity. More recently, Hofer et al. found that fatty acid-binding proteins (Fabps) enhanced the ability of ATGL/CGI-58-mediated lipolysis to trigger PPAR signaling. In this study, CGI-58 interacts with Fabp4 to induce the activity of PPAR $[$ [40]. Maybe the Fabps are potential mediators in our study to link CGI-58 and PPAR $\gamma$. In our previous research, macrophages with CGI-58 overexpression produced more PPAR $\gamma$ mRNA and protein [6]. Moreover, silencing of CGI-58 in macrophages caused downregulation in mRNA levels of PPAR $\gamma$ [13]. However the reason for which CGI-58 positively regulated PPAR $\gamma$ transcription had not been elucidated in these studies. Genome-wide profiling of H3K9ac (Acetylation in histone H3 lysine9) and H3K27ac (Acetylation in histone H3 lysine27) reveals that histone acetylationare highly induced on the $P P A R \gamma$ gene locus during 3T3-L1 differentiation and correlate with PPAR $\gamma$ gene expression [41]. The acetylation of core histones allows DNA to unfold and provides access for transcription factors to bind to their targeted promoters. The turnover of acetylated histones is regulated by the opposing actions of histone acetyltransferases (HATs) and HDACs, with HATs generally allowing transcription and 


\section{Cellular Physiology \\ Cell Physiol Biochem 2016;38:696-713 \\ \begin{tabular}{l|l}
\hline DOI: $10.1159 / 000443027$ & C 2016 The Author(s). Published by S. Karger AG, Basel
\end{tabular} and Biochemistry Published online: February 15, 2016 www.karger.com/cpb \\ Yang et al.: Macrophage CGI-58 Inhibits Inflammation}

Fig. 9. Proposed model of CGI-58/PPAR $\gamma$ signaling. CGI-58 inhibits the recruitment of HDAC2 to the $P P A R \gamma$ promoter, thus resulting in enhanced PPAR $\gamma$ expression and activity, and ultimately suppresses ROS overproduction, mitochondrial dysfunction, and inflammation.

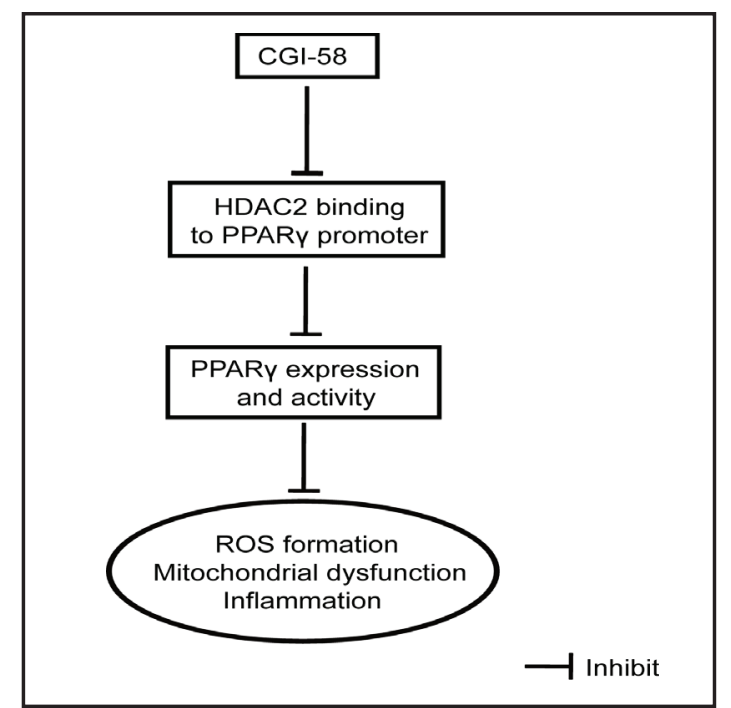

HDACs repressing transcription. In our study, global HDAC activity was clearly affected by the differential expression of CGI-58 (Fig. 7A), and a broad inhibitor of HDACs, TSA, has been shown to reverse the CGI-58 deficiency-induced inhibition of PPAR $\gamma$ expression in a dosedependent manner (Fig. 7B), suggesting a crucial role for HDACs in the regulation of PPAR $\gamma$ expression. Interestingly, overexpression and knockdown of CGI-58 decreased and increased, respectively, the binding of HDAC2 to the promoter of $P P A R \gamma$ (Fig. 7C and D). Accordingly, Ac$\mathrm{H} 3$ was regulated in a manner opposite to the regulation of HDAC2 (Fig. 7C and D). However, it seemed that this alteration did not have as clear of an impact as the recruitment of HDAC1 to the $P P A R \gamma$ promoter (Fig. 7C and D). Thus, our findings indicate that histone acetylation and the removal of HDAC2 from the PPAR $\gamma$ promoter may be involved in the CGI-58-induced PPAR $\gamma$ transcription. A study provided evidence that oxidative signals directly regulate not only the transcription of PPAR $\gamma$ but also PPAR $\gamma$ activity in vascular endothelial cells [42]. In our study, CGI-58 dampened ROS formation and mitochondrial dysfunction. Perhaps the oxidative stress is also involved in the alteration of PPAR $\gamma$ signaling by CGI-58. In the context of our study, both PPAR $\gamma$ expression and activity were promoted by CGI-58. It is likely that the effects of CGI-58 on PPAR $\gamma$ signaling are regulated not only by PPAR $\gamma$ expression but also by the generation of endogenous PPAR $\gamma$ ligands to activate PPAR $\gamma$. Therefore, the mechanisms by which CGI-58 promotes PPAR $\gamma$ signaling are probably complex. We think that further studies are needed to discover other potential mediators and events, such as some endogenous FA derivatives and novel Fabps.

In summary, our study suggests that the potential anti-inflammatory properties of CGI58 in macrophages might be attributed to its ability to induce PPAR $\gamma$ expression by inhibiting the recruitment of HDAC2 to the PPAR $\gamma$ gene promoter (Fig. 9). These findings provide us with a better understanding of the biological actions of CGI-58 in inflammatory regulation and a novel mechanism within these processes.

\section{Acknowledgements}

This study is supported by grants from the National Natural Science Foundation of China (81370961). The funders had no role in study design, data collection and analysis, decision to publish, or preparation of the manuscript.

\section{Disclosure Statement}

None. 


\section{Cellular Physiology \\ Cell Physiol Biochem 2016;38:696-713 \\ \begin{tabular}{l|l}
\hline DOI: $10.1159 / 000443027$ & C 2016 The Author(s). Published by S. Karger AG, Basel
\end{tabular} and Biochemistry Published online: February 15, 2016 www.karger.com/cpb}

Yang et al.: Macrophage CGI-58 Inhibits Inflammation

\section{References}

1 Simon GM, Cravatt BF: Endocannabinoid biosynthesis proceeding through glycerophospho-n-acyl ethanolamine and a role for alpha/beta-hydrolase 4 in this pathway. J Biol Chem 2006;281:26465-26472.

2 Lass A, Zimmermann R, Haemmerle G, Riederer M, Schoiswohl G, Schweiger M, Kienesberger P, Strauss JG, Gorkiewicz G, Zechner R: Adipose triglyceride lipase-mediated lipolysis of cellular fat stores is activated by cgi-58 and defective in chanarin-dorfman syndrome. Cell Metab 2006;3:309-319.

3 Lefevre C, Jobard F, Caux F, Bouadjar B, Karaduman A, Heilig R, Lakhdar H, Wollenberg A, Verret JL, Weissenbach J, Ozguc M, Lathrop M, Prud'homme JF, Fischer J: Mutations in cgi-58, the gene encoding a new protein of the esterase/lipase/thioesterase subfamily, in chanarin-dorfman syndrome. Am J Hum Genet 2001;69:1002-1012.

4 Montero-Moran G, Caviglia JM, McMahon D, Rothenberg A, Subramanian V, Xu Z, Lara-Gonzalez S, Storch J, Carman GM, Brasaemle DL: Cgi-58/abhd5 is a coenzyme a-dependent lysophosphatidic acid acyltransferase. J Lipid Res 2010;51:709-719.

5 McMahon D, Dinh A, Kurz D, Shah D, Han GS, Carman GM, Brasaemle DL: Comparative gene identification 58/alpha/beta hydrolase domain 5 lacks lysophosphatidic acid acyltransferase activity. J Lipid Res 2014;55:1750-1761.

6 Xie P, Zeng X, Xiao J, Sun B, Yang D: Transgenic cgi-58 expression in macrophages alleviates the atherosclerotic lesion development in apoe knockout mice. Biochim Biophys Acta 2014;1841:1683-1690.

7 Wardle EN: Ppar: Receptors that regulate inflammation. Saudi J Kidney Dis Transpl 2004;15:1-6.

8 Usuda D, Kanda T: Peroxisome proliferator-activated receptors for hypertension. World J Cardiol 2014;6:744-754.

9 Aflaki E, Radovic B, Chandak PG, Kolb D, Eisenberg T, Ring J, Fertschai I, Uellen A, Wolinski H, Kohlwein SD, Zechner R, Levak-Frank S, Sattler W, Graier WF, Malli R, Madeo F, Kratky D: Triacylglycerol accumulation activates the mitochondrial apoptosis pathway in macrophages. J Biol Chem 2011;286:7418-7428.

10 Handy DE, Loscalzo J: Redox regulation of mitochondrial function. Antioxid Redox Signal 2012;16:13231367.

11 Yang D, Guo S, Zhang T, Li H: Hypothermia attenuates ischemia/reperfusion-induced endothelial cell apoptosis via alterations in apoptotic pathways and jnk signaling. FEBS Lett 2009;583:2500-2506.

12 Lord CC, Betters JL, Ivanova PT, Milne SB, Myers DS, Madenspacher J, Thomas G, Chung S, Liu M, Davis MA, Lee RG, Crooke RM, Graham MJ, Parks JS, Brasaemle DL, Fessler MB, Brown HA, Brown JM: Cgi-58/abhd5derived signaling lipids regulate systemic inflammation and insulin action. Diabetes 2012;61:355-363.

13 Miao H, Ou J, Ma Y, Guo F, Yang Z, Wiggins M, Liu C, Song W, Han X, Wang M, Cao Q, Chung BH, Yang D, Liang H, Xue B, Shi H, Gan L, Yu L: Macrophage cgi-58 deficiency activates ros-inflammasome pathway to promote insulin resistance in mice. Cell Rep 2014;7:223-235.

14 Miao H, Ou J, Zhang X, Chen Y, Xue B, Shi H, Gan L, Yu L, Liang H: Macrophage cgi-58 deficiency promotes il-1beta transcription by activating the socs3-foxo1 pathway. Clin Sci (Lond) 2015;128:493-506.

15 Kim KA, Gu W, Lee IA, Joh EH, Kim DH: High fat diet-induced gut microbiota exacerbates inflammation and obesity in mice via the tlr4 signaling pathway. PloS One 2012;7:e47713.

16 Fischer J, Lefevre C, Morava E, Mussini JM, Laforet P, Negre-Salvayre A, Lathrop M, Salvayre R: The gene encoding adipose triglyceride lipase (pnpla2) is mutated in neutral lipid storage disease with myopathy. Nat Genet 2007;39:28-30.

17 Guo F, Ma Y, Kadegowda AK, Betters JL, Xie P, Liu G, Liu X, Miao H, Ou J, Su X, Zheng Z, Xue B, Shi H, Yu L: Deficiency of liver comparative gene identification-58 causes steatohepatitis and fibrosis in mice. J Lipid Res 2013;54:2109-2120.

18 Radner FP, Streith IE, Schoiswohl G, Schweiger M, Kumari M, Eichmann TO, Rechberger G, Koefeler HC, Eder S, Schauer S, Theussl HC, Preiss-Landl K, Lass A, Zimmermann R, Hoefler G, Zechner R, Haemmerle G: Growth retardation, impaired triacylglycerol catabolism, hepatic steatosis, and lethal skin barrier defect in mice lacking comparative gene identification-58 (cgi-58). J Biol Chem 2010;285:7300-7311.

19 Wu JW, Wang SP, Alvarez F, Casavant S, Gauthier N, Abed L, Soni KG, Yang G, Mitchell GA: Deficiency of liver adipose triglyceride lipase in mice causes progressive hepatic steatosis. Hepatology 2011;54:122-132.

20 Brown JM, Betters JL, Lord C, Ma Y, Han X, Yang K, Alger HM, Melchior J, Sawyer J, Shah R, Wilson MD, Liu X, Graham MJ, Lee R, Crooke R, Shulman GI, Xue B, Shi H, Yu L: Cgi-58 knockdown in mice causes hepatic steatosis but prevents diet-induced obesity and glucose intolerance. J Lipid Res 2010;51:3306-3315. 


\section{Cellular Physiology Cell Physiol Biochem 2016;38:696-713 \begin{tabular}{ll|l} 
DOI: 10.1159/000443027 & $\begin{array}{l}\text { @ 2016 The Author(s). Published by S. Karger AG, Basel } \\
\text { www.karger.com/cpb }\end{array}$ \\
\hline
\end{tabular}}

Yang et al.: Macrophage CGI-58 Inhibits Inflammation

21 Wymann MP, Schneiter R: Lipid signalling in disease. Nat Rev Mol Cell Biol 2008;9:162-176.

22 Hla T, Lee MJ, Ancellin N, Paik JH, Kluk MJ: Lysophospholipids--receptor revelations. Science 2001;294:1875-1878.

23 Fang Y, Vilella-Bach M, Bachmann R, Flanigan A, Chen J: Phosphatidic acid-mediated mitogenic activation of mtor signaling. Science 2001;294:1942-1945.

24 Zierler KA, Zechner R, Haemmerle G: Comparative gene identification-58/alpha/beta hydrolase domain 5: More than just an adipose triglyceride lipase activator? Curr Opin Lipidol 2014;25:102-109.

25 Aflaki E, Balenga NA, Luschnig-Schratl P, Wolinski H, Povoden S, Chandak PG, Bogner-Strauss JG, Eder S, Konya V, Kohlwein SD, Heinemann A, Kratky D: Impaired rho gtpase activation abrogates cell polarization and migration in macrophages with defective lipolysis. Cell Mol Life Sci 2011;68:3933-3947.

26 Das SK, Chakrabarti R: Role of ppar in cardiovascular diseases. Recent Pat Cardiovasc Drug Discov 2006;1:193-209.

27 Kiss M, Czimmerer Z, Nagy L: The role of lipid-activated nuclear receptors in shaping macrophage and dendritic cell function: From physiology to pathology. J Allergy Clin Immunol 2013;132:264-286.

28 Montanez JE, Peters JM, Correll JB, Gonzalez FJ, Patterson AD: Metabolomics: An essential tool to understand the function of peroxisome proliferator-activated receptor alpha. Toxicol Pathol 2013;41:410418.

29 Glass CK, Saijo K: Nuclear receptor transrepression pathways that regulate inflammation in macrophages and t cells. Nat Rev Immunol 2010;10:365-376.

30 Hong C, Tontonoz P: Coordination of inflammation and metabolism by ppar and lxr nuclear receptors. Curr Opin Genet Dev 2008;18:461-467.

31 Wilson JL, Duan R, El-Marakby A, Alhashim A, Lee DL: Peroxisome proliferator activated receptoralpha agonist slows the progression of hypertension, attenuates plasma interleukin-6 levels and renal inflammatory markers in angiotensin ii infused mice. PPAR Res 2012;2012:645969.

32 Zarzuelo MJ, Jimenez R, Galindo P, Sanchez M, Nieto A, Romero M, Quintela AM, Lopez-Sepulveda R, Gomez-Guzman M, Bailon E, Rodriguez-Gomez I, Zarzuelo A, Galvez J, Tamargo J, Perez-Vizcaino F, Duarte J: Antihypertensive effects of peroxisome proliferator-activated receptor-beta activation in spontaneously hypertensive rats. Hypertension 2011;58:733-743.

33 Nagao S, Yamaguchi T: Ppar-gamma agonists in polycystic kidney disease with frequent development of cardiovascular disorders. Curr Mol Pharmacol 2012;5:292-300.

34 Duan SZ, Usher MG, Mortensen RM: Ppars: The vasculature, inflammation and hypertension. Curr Opin Nephrol Hypertens 2009;18:128-133.

35 Meng Y, Chen C, Tian C, Du J, Li HH: Angiotensin ii-induced egr-1 expression is suppressed by peroxisome proliferator-activated receptor-gamma ligand 15d-pgj(2) in macrophages. Cell Physiol Biochem 2015;35:689-698.

36 Wang S, Sun Z, Zhang X, Li Z, Wu M, Zhao W, Wang H, Chen T, Yan H, Zhu J: Wnt1 positively regulates cd36 expression via tcf4 and ppar-gamma in macrophages. Cell Physiol Biochem 2015;35:1289-1302.

37 Goeritzer M, Schlager S, Radovic B, Madreiter CT, Rainer S, Thomas G, Lord CC, Sacks J, Brown AL, Vujic N, Obrowsky S, Sachdev V, Kolb D, Chandak PG, Graier WF, Sattler W, Brown JM, Kratky D: Deletion of cgi58 or adipose triglyceride lipase differently affects macrophage function and atherosclerosis. J Lipid Res 2014;55:2562-2575.

38 Hock MB, Kralli A: Transcriptional control of mitochondrial biogenesis and function. Annu Rev Physiol 2009;71:177-203.

39 Badin PM, Loubiere C, Coonen M, Louche K, Tavernier G, Bourlier V, Mairal A, Rustan AC, Smith SR, Langin D, Moro C: Regulation of skeletal muscle lipolysis and oxidative metabolism by the co-lipase cgi-58. J Lipid Res 2012;53:839-848.

40 Hofer P, Boeszoermenyi A, Jaeger D, Feiler U, Arthanari H, Mayer N, Zehender F, Rechberger G, Oberer M, Zimmermann R, Lass A, Haemmerle G, Breinbauer R, Zechner R, Preiss-Landl K: Fatty acid-binding proteins interact with comparative gene identification-58 linking lipolysis with lipid ligand shuttling. J Biol Chem 2015;290:18438-18453.

41 Lee JE, Ge K: Transcriptional and epigenetic regulation of ppargamma expression during adipogenesis. Cell Biosci 2014;4:29.

42 Blanquicett C, Kang BY, Ritzenthaler JD, Jones DP, Hart CM: Oxidative stress modulates ppar gamma in vascular endothelial cells. Free Radic Biol Med 2010;48:1618-1625. 